\title{
CONTROVERSY
}

\section{Response: questions of science, law and ethics}

\author{
AMAR JESANI
}

Coordinator, Centre for Studies in Ethics and Rights (an institute of Anusandhan Trust), 4th floor Candelar, 26 St John Baptist Road, Bandra West, Mumbai 400050 INDIA e-mail: jesani@gmail.com

My editorial (1) criticised forensic scientists, medical professionals and behavioural scientists who are involved in police interrogation techniques that use scientifically questionable methods and technologies. I sent a copy of my editorial to the director of the Bangalore Forensic Science Laboratories (BFSL) and to some other forensic doctors and experts, asking for their comments. The responses by Dr BM Mohan (2) and Dr Jagadeesh N (3) are much appreciated as there is a need for public discussion of this subject.

Dr Mohan's comments cover three major areas of dispute: (a) the scientific aspects of forensic technologies and methods used in police interrogation; (b) the legal aspects and (c) the ethics of scientists and doctors participating in such interrogation. I will attempt a response to his statements on these three subjects.

\section{Scientific aspects of forensic technologies}

Scientific aspects of polygraph and lie-detection have been examined by two expert committees. The first report was prepared by an expert committee of the National Research Council (NRC) at the request of the United States Department of Energy (4) in 2003. The second report was prepared by a working party of the British Psychological Society (BPS) in 2004 (5). The NRC expert committee was asked to review the use of the polygraph for personnel screening, but also reviewed its use in criminal investigation or "specific-event investigation". The BPS working party reviewed evidence on all uses of the polygraph, and looked at its scientific validity (the extent to which it measures what it is supposed to measure) as well as its scientific reliability (its consistency across time and when used by different examiners). While neither of these reports dismisses lie detection technologies, both of them describe their limitations and note the need to use them with caution.

According to the NRC report, "Almost a century of research in scientific psychology and physiology provides little basis for the expectation that a polygraph test could have extremely high accuracy. Although psychological states often associated with deception (eg, fear of being judged deceptive) do tend to affect the physiological responses that the polygraph measures, these same states can arise in the absence of deception. Moreover, many other psychological and physiological factors (eg, anxiety about being tested) also affect those responses. Such phenomena make polygraph testing intrinsically susceptible

Jesani A. Response: questions of science, law and ethics. Indian J Med Ethics 2007; $3: 10$. to producing erroneous results. This inherent ambiguity of the physiological measures used in the polygraph suggests that further investments in improving polygraph technique and interpretation will bring only modest improvements in accuracy... Research has not developed and tested theories of the underlying factors that produce the observed responses." (4, page 2)

The BPS working party's conclusion on the use of the polygraph in criminal investigation is equally severe:"A polygraph does not detect lies, but only arousal which is assumed to accompany telling a lie ... a pattern of physiological activity directly related to lying does not exist ... (the) most popular lie detection procedures ... are built upon the premise that, while answering so-called 'relevant' questions, liars will be more aroused than while answering so-called 'control' questions, due to a fear of detection (fear of getting caught lying). This premise is somewhat naive as truth tellers may also be more aroused when answering the relevant questions, particularly: (i) when these relevant questions are emotion evoking questions ... and (ii) when the innocent examinee experiences fear, which may occur, for example, when the person is afraid that his or her honest answers will not be believed by the polygraph examiner." (5, page 10)

The problem of false positive and false negative findings is compounded by what are called "counter-measures": when examinees manipulate their physiological responses in order to get examiners to conclude that they are telling the truth. One well-known example is that of Floyd Fay, who was falsely convicted of murder in the USA on the basis of a failed polygraph examination. (He served two and a half years before the real killers were found.) When in prison, he learned to defeat a polygraph examination, and then taught inmates this skill. Of the 27 inmates trained for just 20 minutes each, 23 defeated the test.

Thus, polygraph and other such tests for lie detection and finding the truth do lie.

Both the US and the UK committees came down heavily on the quality of scientific evidence. They noted that most studies were of "low" quality, and there was a significant potential for bias and conflict of interest in polygraph research as the bulk of research had been funded by agencies that rely on the polygraph for law enforcement or counterintelligence purposes.

It is important to note that evidence from polygraph and narco 
analysis testing is not admissible in a court. Why is it being relied on? Is it that law enforcement agencies want to misguide the public that something is being done?

Interestingly, despite reports of research on narco analysis, and its recent increased use in criminal investigation, there is little systematic scientific review of this practice. The question is: how have narco analysis and lie-detection technologies become "scientific" tools of police interrogation, with strong adherents among forensic scientists, without any scientific backing? Part of the answer lies in the complex relationship between the science and the law.

\section{Science and the law}

It is my impression that many of the forensic technologies that are used by police and the intelligence communities and generally accepted by the courts have not been examined rigorously by the scientific community. At some point the courts will have to look at the validity and reliability of these technologies. Research must be done in these technologies by scientists who do not have conflicts of interest in the subject.

In the meanwhile the role of forensic scientists is to assist the court in appreciating the problems in validity and reliability of the technology used in investigation. In this context I find Dr Mohan's assertions worrisome. If the forensic scientist is not candid about the limitations of the technology this will contribute to creating misconceptions among people and misguide the courts. The claim by investigating agencies that $96-$ 97 per cent of their cases were solved using these technologies is not supported by available research data. Such agencies have an interest in asserting the "success rates" of such technologies. We need scientists who do not have conflicts of interest in this matter to make research-based comments on the technique's validity and reliability.

I must emphasise that this is not only about scientific validity. Any inquiry must follow due process - this is a right of the accused. If narco analysis involves a violation of human rights, then it is inhumane, however efficacious it might be or become. In fact, many torture methods are scientifically designed, just as technologies for legal executions are scientifically designed. Scientific technologies deployed for inflicting torture do not become humane just because they are scientific.

There are a number of legal opinions, like that of Linda Keller cited in my editorial, that narco analysis, which is a drug-induced confession, is a coercive interrogation practice and falls within the United Nations' definition of torture. This would violate substantive due process - and this goes beyond the absence of judicial order. We must keep in mind that there was a time when the judiciary did not consider torture a violation of due process. This change in the understanding of the court resulted from advances in the political and human rights spheres.

\section{Ethics of participation}

A core ethical requirement for forensic doctors and scientists is impartiality. They must not allow their conduct and opinion to be influenced by their employers, by investigating agencies or even by a feeling of "national interest". The only way forensic laboratories can stay scientific and not be reduced to police laboratories is by upholding this principle.

However, forensic doctors and scientists are often perceived as being an integral part of the state apparatus, specifically the police and intelligence agencies. The dilemma that they face, of dual loyalties, is acute but seldom discussed. If they make errors of judgment, if they are partial or have a misplaced loyalty towards law enforcement agencies, or if they succumb to an ideological temptation to fight terrorism in defence of national interests-all this can lead to compromises in ethical and human rights standards (6).

Dr Mohan describes in detail the narco analysis procedure and the role played by each person involved. He shows that narco analysis requires the actual presence and active participation of the medical team. The medical team is not absolved of complicity just because the actual questioning is carried out by a forensic psychologist and not physicians, just as a doctor witnessing a policeman torturing a victim is himself guilty of torture.

I fail to understand Dr Mohan's contention that when the medical team is so deeply involved in interrogation, it is not participating in interrogation, and thus not violating medical ethics.

\section{References}

1. Jesani A. Medical professional and interrogation: Lies about finding the truth. Indian J Med Ethics 2006 Oct-Dec; 3: 116-117.

2. Mohan BM. Misconceptions about narco analysis. Indian J Med Ethics 2007; 3:7-8.

3. Jagadeesh N. Narco analysis leads to more questions than answers. Indian J Med Ethics 2007; 3: 9.

4. National Research Council. Committee to review the scientific evidence on the polygraph. Washington DC: National Academies Press; 2003.

5. BPS Working Party. A review of the current scientific status and fields of application of polygraphic deception detection. London: The British Psychological Society; 2004.

6. British Medical Association. The medical profession and human rights: handbook for a changing agenda. London:Zed Books and BMA; 2001. 